\title{
The Language Commons: An Innovative Space Supporting Second Language Acquisition
}

\author{
Judith A. Giering \\ University of Virginia \\ jgiering@virginia.edu \\ Hope Fitzgerald \\ University of Virginia \\ hf6v@,virginia.edu
}

\begin{abstract}
In 2015, language faculty and administrators at the University of Virginia met to evaluate the needs of the more than 20 language programs offered on campus. A priority emerged for languagelearning space better equipped to facilitate authentic interaction and communication. The committee conceived of an alternative language-learning space that would be motivating, collaborative, and inviting and offer a variety of technologies in support of innovative teaching and learning. Now in its second year of operation, the Language Commons facilitates formal and informal learning activities for students and faculty that are aligned with current theory and practice in second language acquisition. Language faculty utilize the space for innovative instructional activities that might otherwise be limited by small, inflexible classroom spaces. This article describes the development of the Language Commons from initial conception through design and the rich array of activities occurring in the space, featuring examples of faculty uses of commons spaces and technologies. Preliminary outcomes suggest the Commons is valued for its support of student motivation, lowering of anxiety, and opportunities for community engagement and as a place to disrupt classroom hierarchies and routines.
\end{abstract}

Keywords: anxiety, authentic learning, design, motivation, second language acquisition, student centered.

World language study has long been an integral part of a liberal education. The Modern Language Association (2011) has emphasized the importance of language study for purposes of communication, cultural appreciation, economic opportunity, enriching public discussion of current affairs, and humanistic research and inquiry. With over 20 world languages offered, the College of Arts \& Sciences (College) at the University of Virginia is committed to students learning a second language. It is a vital part of the College's goals to prepare undergraduate students to be global citizens and participate in a connected, globalizing society; thus language study emphasizes the inseparability of language and culture, building students' linguistic and intercultural communication skills. The scope of the College's language education is not small; students are required to take four semesters of their chosen language. Each year, approximately 3,000 students are enrolled in first- and second-level language courses. Additionally, nearly 200 students major in a world language each year, and about 100 are currently pursuing a graduate degree in a language program. The College's longstanding commitment to world language instruction remains strong in spite of a growing trend nationwide to limit language requirements or cut them entirely and close language departments.

While a commitment to world language study has remained steady, the means through which world languages are taught have evolved over time. As teaching in higher education has generally moved to a more student-centered approach, so has the teaching of world languages. Pedagogical developments such as the widespread adoption of the "communicative approach," with its emphasis on the centrality of meaningful communication to the language learning process, a more intentional 
integration of cultural proficiency, and the use of technology, have all impacted the classroom experience for both faculty and students. The College has sought to support these changes through a variety of means, including faculty development in pedagogy and course design, adoption of multiple learning technologies, and most recently, an investment in the spaces faculty and students use for both formal language instruction and informal activities supporting language acquisition. Importantly, work and thinking in each of these areas has informed the others. In this article we describe the development of the Language Commons, a dynamic and flexible space that facilitates language learning, from initial conception through design and the rich array of activities occurring in the space.

\section{Development of the Language Commons Concept}

Over a period of several years leading up to fall 2014, concerns arose about the state of the College's language lab. At that time, it was a 48-student space to which faculty brought students for skill and drill activities and assessments. In partnership with the lab, an office supplied faculty and students with technology such as cameras and audio recorders that could be checked out to complete projects. Several challenges existed that needed to be addressed with varying degrees of urgency. First, the lab was facing infrastructure problems in a historic 1898 building. Second, faculty were asking for the ability to conduct other activities in the lab that the technology and staffing were not able to support. Third, the language software licensed to the lab was no longer going to be supported by the vendor, necessitating a search for a new software solution. Fourth, the equipment inventory was becoming unwieldy, with a stash of outdated equipment and not enough funds to update the equipment most in demand. Finally, it was clear that peer universities were moving ahead in reconceiving language labs, and that the lab no longer supported the most current thinking about pedagogy and technology for language teaching and learning.

In response to these challenges, College leadership formed a committee in fall 2014 to assess the current spaces for language learning, investigate peer institutions and best practices around the country, solicit feedback from language faculty, and ultimately make a recommendation on what type of space would best support the goals of language acquisition and pursuit of language degrees. The committee comprised the associate dean for Arts \& Humanities, four full-time language faculty, the director of the language lab, the director of Learning Design \& Technology, and the director of Space Planning and Management. The committee undertook a number of activities as part of their work. They invited faculty from peer institutions that had already rethought their language labs to campus to discuss those spaces; conducted literature reviews about how space might positively impact pedagogical goals in language teaching; interviewed staff who worked in the lab; and held three town hall meetings for language faculty. The town hall meetings were especially important to the committee, to ensure the faculty voice be strongly represented in their final analysis. At the completion of these activities, the committee wrote a report for the dean with multiple recommendations, including the creation of a so-called Language Commons.

\section{Rationale: Language Learning Spaces in 21st Century Higher Education}

Developments in second language acquisition (SLA) theory and practice, along with fundamental shifts in learning technologies, have led to new expectations for language learning spaces in higher education and forced traditional labs to reimagine their role in teaching and learning. From their inception in the 1950s, the mission of these labs was to provide access to technology in support of language learning; however, language-learning spaces are no longer limited by this singular goal. Today, language spaces and centers are being asked to take on new roles beyond technology provision and support. Kronenberg (2017) describes this new model as "moving away from massive technology 
installations to more flexible, more adaptable, more diverse spaces. Technology is not necessarily the only focus of language centers, but rather one (albeit often very important) aspect" (p. 162).

Concurrent with changes to the purpose of language labs and centers, developments in SLA theory and practice have influenced the activities taking place in language spaces. Previously, language lab use was largely informed by the audiolingual approach to language teaching. Based in behaviorism and structural linguistics (O'Maggio-Hadley, 2001), audiolingualism relied largely on repetition, memorization, and rote conversation, limiting learners' authentic communicative practice. More recent understandings of language teaching and learning emphasize learners' development of language proficiency - that is, what individuals can "do" with language in spontaneous contexts (American Council on the Teaching of Foreign Languages, 2012). Approaches that can broadly be labeled "proficiency oriented" or "communicative" emphasize the use of authentic, interactive communicative tasks and outcome-oriented activities to engage learners.

Research into affective and metacognitive factors in language acquisition has likewise affected the teaching and learning of world languages. Motivation has been found to be a strong predictor of language-learning success (Skehan, 1989). Erham, Leaver, and Oxford (2003) argued that "providing students with learning experiences that meet their needs for competence, relatedness, self-esteem, and enjoyment" (p. 320) can increase intrinsic motivation to learn a new language, suggesting that learning environments and activities may influence student motivation and, subsequently, success in language development. Anxiety, including anxiety that is specific to language learning, has long been considered to significantly impede the development of world language fluency and performance (Horwitz, Horwitz, \& Cope, 1986). Acknowledging and mitigating the effects of this anxiety have become the goals of classroom practitioners eager to encourage student success (see, for example, Young, 1991).

When it came time to envision a new role for our aging language lab (see Figure 1), it quickly became clear that the needs of faculty were in alignment with these more recent developments in SLA theory and pedagogical practice. The former lab was instructor centered both in design and in use, with individual, walled computer stations that obstructed face to face interaction. Pedagogical use of the lab was, therefore, limited by the space itself, with the most common uses being assessment, pronunciation, and drill activities. As a physically inflexible space, the lab struggled to offer faculty the freedom to explore new approaches and new learning activities. Those heavily involved in redesign discussions, with input from faculty and outside experts from language centers across the country, envisioned a space where students would feel welcomed to engage in communicative, collaborative learning activities more in line with current SLA theory and practice. By engaging students in more authentic interactions, these activities would enhance motivation and interest among learners.

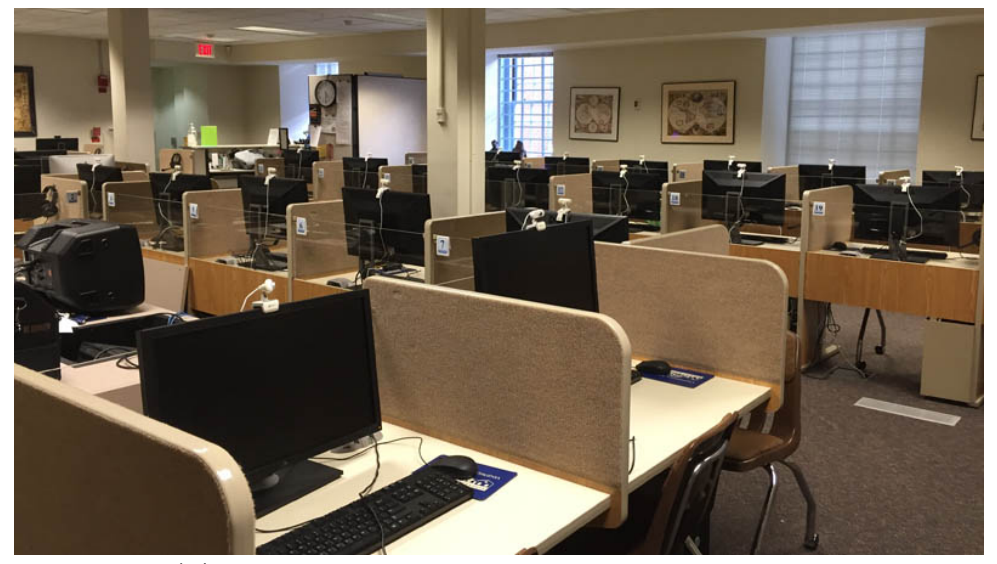

Figure 1. The language lab, prior to renovation. Computer stations were separated, minimizing opportunities for interaction. 
Beyond providing a welcoming environment, the new space would need to support the efforts of our most innovative faculty, providing nontraditional space, flexible furnishings, and varied resources that would facilitate teaching and learning. It would also need to be spacious enough to accommodate learning activities that could not be accomplished in typical classrooms because of room size, noise interference, or lack of technology. Faculty input also indicated continued interest in a traditional lab space to support specific activities-particularly oral assessment in the College's largest language programs. Thus, a redesigned language-learning space would need to balance some traditional lab activities while opening up opportunities for pedagogical innovation.

\section{Building the Language Commons}

Once the recommendation regarding the Language Commons was accepted by College leadership, implementation was turned over primarily to three professional staff at the College: the directors of space planning and management, learning design \& technology, and computing services. These staff members worked collaboratively to build out the Language Commons, outfit it with appropriate technology and furniture, staff it, and begin to imagine strategies for engaging faculty and students in the mission and activities of the space. Capital expenses for the project were mostly funded by a significant donation to the College for innovative pedagogical initiatives. An operational budget for the ongoing work of the Language Commons was developed, and it was determined that the director of learning design \& technology would oversee this budget, as well as staffing and programming for the Commons.

The lengthy process of rebuilding the lab also included university architects and space designers, information technology services, design consultants, technology suppliers, furnishing vendors, and instructional designers in the College. The new Language Commons was developed in the space of the former language lab, a large rectangular room of nearly 2,000 square feet. On the second floor of a historic building, the space featured high ceilings and a wall of large windows with deep window wells. With the old technology and furniture installations removed, the room was clearly an attractive space with great potential for the new design team. Being located in the same building as the majority of the College language programs made it easily accessible to language classes and their students.

Function, rather than technology, informed the design of the space. The new Commons was created to accommodate several specific uses (class activities, group work, language enrichment/enjoyment, digital project development, presentations of varying sizes) while remaining flexible for as-yet unimagined uses. The final design thus included small group huddle spaces, sounddampened couch corners for study and discussion, conversation pods with large comfortable chairs, tall group-work tables, and computer workstations, as well as a front desk to be staffed by a student employee (Figure 2). Also incorporated were the hardware and software to support these functions, including monitors with wired and wireless displays, a simple video production space, laser projectors, PC and Mac computers, and a speaker system. 


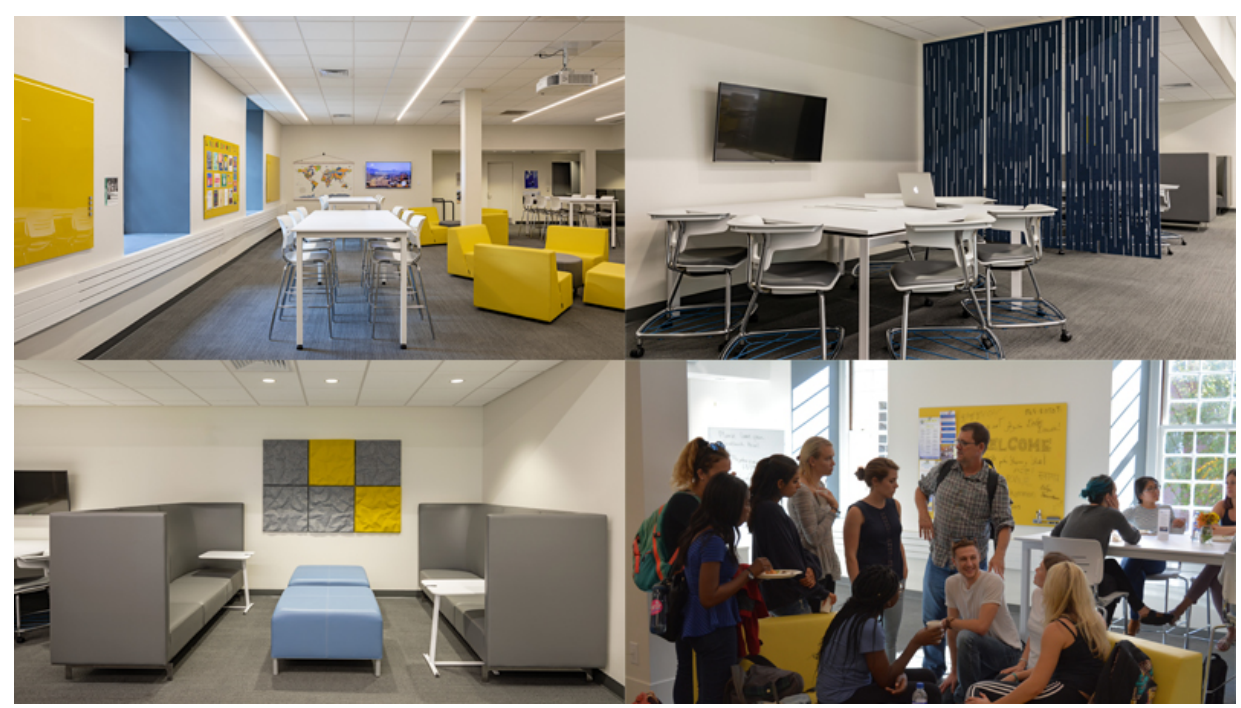

Figure 2. The Language Commons. (Clockwise from top left): standing height tables, group work areas with wall-mounted monitors, conversation pods, couch corners.

With the understanding that the Language Commons would serve not as a technology provider, but rather as a teaching and learning resource hub in the world language ecosystem at the College, the space also incorporated resources identified by instructional designers, faculty, and students to support and celebrate language use. Such resources include multilingual board game and fiction collections, international TV access, immersive technologies (virtual reality headsets and augmented reality resources), and a teaching resource cart ${ }^{1}$ of supplies for use in the Commons and/or in the classroom.

A concurrent restructuring of computing services in the College allowed for additional space (a conference room and storage space) to be redeveloped into a small language lab with a more traditional teacher-fronted design. The addition of SANS language lab software (SANS Inc., 2019) to the new lab has enhanced this environment as well, by enabling more student-to-student interaction than was common in the previous lab setup. The new 24-station lab was less than half the size of the previous lab, but large enough to accommodate nearly all language courses in the College. Despite its traditional layout, the new lab is being used for a wider variety of activities, including paired conversation, self-evaluation, research in the target language, and cultural explorations.

\section{The Language Commons in Use}

The Language Commons opened in fall 2017, with a week of language and culture activities to draw users into the new space. Since its opening, the Commons has become central to the instructional activities of multiple language courses and programs. To date, 13 of the College's language programs have utilized the Commons for class sessions or departmental activities. Student conversation clubs, dance troupes, tutors, and cultural associations also use the space for language and culture activities. It is hoped that by facilitating these activities, and through programming designed by staff, the Commons will play an active role in extending language learning far beyond the classroom. Activities supported in the Commons have aimed to foster authentic collaboration and interaction, lower learner anxiety, increase community engagement, and enhance motivation, while also providing opportunities for explorations of new approaches to teaching.

\footnotetext{
${ }^{1}$ The teaching resources cart includes "maker" activity supplies, lap boards, maps, games, and other tools to support interaction and communication in language classes.
} 


\section{Fostering Authentic Collaboration and Interaction}

Utilizing the Language Commons has added an element of authenticity to the transactional speaking and listening activities that often form the core of communicative language classes. Japanese language courses, for example, regularly use the Commons as a space for interaction and collaboration across multi-section courses. Students use group work spaces to engage with peers in cross-section conversational and presentational activities, promoting authentic exchange among students who do not know each other well. Adding new students to the familiar class group in this way encourages students to carefully listen and practice asking for clarification, to successfully interact with unfamiliar interlocutors. Other faculty have remarked that the Commons fosters conversational activities that feel less authentic in a traditional classroom space. One Spanish language instructor, reflecting on her students' experience with speaking activities in the Commons, remarked that "it feels more realistic and authentic to have a conversation in the Commons than in a classroom" where an instructor is monitoring and giving feedback on each interaction (S. Rabke, personal interview, December 11, 2018).

\section{Lowering Anxiety and Stress}

When final exams begin each semester, the Commons sets up a "stress-free zone" and offers a series of study break activities related to language and culture learning. Popular activities, such as construction and painting of a Catalan Caga Tió log in early December, welcome students to practice their language skills, introduce lighthearted cultural information, and provide a fun hands-on "maker" experience. Other activities, such as origami and kirigami, draw crowds of students who learn a new skill and practice language skills in a no-stakes environment.

Mindfulness activities in the Commons have also been used to lower student anxiety and increase positive associations with language learning outside the classroom. In fall 2018, faculty from the Spanish program organized a Jornada de Relajacion, in which they led language students in mindfulness and relaxation activities conducted in Spanish. In addition to such cocurricular stressrelief activities, common class activities in the Commons have also been seen to lower languagelearning anxiety and stress. A Spanish faculty member, after bringing her students to the Commons for speaking activities, noted that students seemed less anxious when engaging in speaking practice, as they were not being overheard by their peers (S. Rabke, personal interview, December 11, 2018). Further investigations of the effects of learning spaces and environments on student anxiety and stress in language classes are forthcoming.

\section{Increasing Community Engagement}

The large and active Japanese language program has regularly fostered interaction with the local Japanese-speaking community. Small classroom sizes placed limits on the number of community members who could participate in such activities, but the open space and large tables in the Commons allow students and community members to meet comfortably for small group conversations. Students enjoy these unique opportunities to develop oral skills and community connections, and later they may reflect on cultural and linguistic aspects of their interactions in course ePortfolios.

\section{Fostering Motivation}

Activities to increase student motivation and interest in language learning, multilingualism, and intercultural communication have been held in the Commons. The most popular of these events to 
date was the Last Language Standing challenge. Held in spring 2017, the challenge encouraged teams to keep their language in use for an entire day. It was an experiment in "competitive language practice" that aimed to encourage language use outside of the classroom through a bit of friendly rivalry. More than 350 students, faculty, and staff participated in the challenge by chatting, eating, playing games, and even performing karaoke in their world languages. Teams representing 12 world languages participated, representing more than half of the College's taught languages. Many faculty and students stayed for hours to participate and proudly displayed winners' certificates on departmental bulletin boards. This will in all likelihood be an annual event.

\section{Supporting Innovation in Language Teaching}

As part of the College's Learning Design \& Technology unit, the Commons' mission also includes a commitment to facilitate course design and support high-quality instruction. Instructional designers work one-on-one with faculty to support course design and pedagogical efforts, and with campus partners to offer workshops for technologies that facilitate language teaching and learning. Course design support, and a materials stipend from the Language Commons, helped one Italian faculty member redesign her third semester final oral exam. Rather than require students to create a formal dialogue with a partner, she organized students into small groups to play board games over the course of two class periods. The instructor moved from group to group to monitor interaction and language use as students engaged in authentic communication with peers to successfully navigate the board games.

In an intensive French writing course, a faculty member invited students to a conversation pod in the Commons to meet for peer review workshops. She used these workshops to coach students through peer review discussions to "model the importance of giving quality feedback" and to show the importance of peer feedback relative to instructor comments (R. Geer, personal email communication, December 11, 2018). The faculty member elected to use the Commons, as opposed to her classroom, to disengage from the built hierarchy associated with classroom spaces. She noted that "the Language Commons felt like a vital space to get away from that built-in hierarchy and the change in physical space felt incredibly helpful for getting them to change their attitudes towards peer review" (R. Geer, December 11, 2018).

\section{Reflecting on the Role of the Language Commons}

\section{A Dedicated Language Space}

Having a dedicated space for language activities has given faculty the room to innovate in their teaching activities and has helped learners feel excited about the languages and cultures they study or to which they belong. Groups of dedicated users have grown among both faculty and students since the opening. In response to feedback requests, student users have said they enjoy having a space that is dedicated to language learning and those who love languages, like themselves. Daily users stake out their spots for studying, group meetings, and lunch dates with friends.

Faculty who routinely use the Commons have noted its importance in providing "a change of scene" that facilitates new learning activities and breaks up the inevitable sense of routine present in the classroom. Though perhaps it should have been foreseen, the use of the Commons as a place to change up routines has been a key feature of its development. Both faculty and students have commented on the importance of having a space with a decidedly "non-classroom" feel, as a place where interactions take on a more authentic character, anxiety decreases, and language use becomes a natural extension of students' activities, rather than a classroom exercise. 
Now entering its fourth semester in operation, the Commons is growing into its role as a hub for language activities, with campus partners recognizing the Commons as a useful space for language and culture events. The Institute for World Languages now holds monthly faculty round table sessions in the Commons. Education Abroad advisors, in coordination with language faculty, conduct occasional study abroad information sessions and program orientations. These and other globally minded campus partners are reaching undergraduate student audiences by connecting their global opportunities to language learning.

\section{Unexpected Uses and Outcomes}

A few of the Commons' features and resources have received a positive response beyond original expectations. The teaching resource cart has been extensively used, particularly by lecturers and graduate students in first- and second-year courses. Beyond the classroom, the cart's supplies have also provided creative resources to occupy small children while parents-faculty and community members — engage with students in learning activities. Likewise, mobile glass boards, located around the room, receive considerable use-and not only by language learners; Molecular models and historical outlines are as likely to fill the boards as verb conjugation charts and dialogues.

The existence of the Commons has also had unexpected "washback" effects on other campus learning spaces. While faculty can bring class groups to the Commons for activities, they cannot reserve the Commons as the official classroom for their courses. Once faculty have experienced the types of activities that a space like the Commons supports and enhances, they began to express dissatisfaction with their regular classrooms; many instructors found their class activities constrained by small classroom sizes and inflexible furniture arrangements. Discussions and research around this problem led to a successful request to the Provost's Office for some modest redevelopment of several classrooms, to better accommodate active learning in language classes and support the sorts of activelearning approaches that were successfully being applied in the Commons.

\section{Challenges}

In transitioning to a Language Commons and a smaller language lab, hard choices had to be made between supporting communicative, interactive language learning and assessment (clearly a priority for many) and accommodating some of the most common uses of the former language lab.

Inevitably, some of the functions performed in the old language lab were lost in the move to the new space, including individual learning activities that require silent or sound-dampened space for intensive listening or pronunciation work.

Developing a large, multiuse space in an historic building has led to some challenges. With an open floor plan, noise carries easily, and the Commons struggles at times to accommodate multiple groups while class activities are taking place. Presentations, in particular, sometimes require imposing a "quiet study" environment in the rest of the Commons so that presenters can be easily heard and not distracted by conversation. Similarly, when the space is sparsely populated, students seem to feel awkward raising their voices in conversational meetings with partners. Scheduling can be challenging, as we seek to accommodate course activities while also welcoming students to study, meet conversation partners, and enjoy the space. These challenges are generally mitigated by moving furniture or playing white noise through the speaker system. 


\section{Conclusion}

Although the planners of the Language Commons had hoped for a space that would be used often for language-learning activities, the innovation and scope of these activities have exceeded initial expectations, creating a dynamic space that builds community and supports pedagogical goals for language learning. The team attributes this primarily to two reasons. First, many voices, particularly faculty, were considered in the planning process. Second, it was determined that function should inform the technology and features of the space, not the other way around. With these two principles guiding continued work and evolution of the space, faculty and students who use the Commons will be limited only by their own imaginations of what is possible.

\section{References}

American Council on the Teaching of Foreign Languages. (2012). ACTFL proficiency guidelines 2012. Retrieved from https://www.actfl.org/publications/guidelines-and-manuals/actflproficiency-guidelines-2012

Erham, M., Leaver, B. L., \& Oxford, R. (2003). A brief overview of individual differences in second language learning. System, 31, 313-330.

Horwitz, E., Horwitz, M. B., \& Cope, J.. (1986). Foreign language classroom anxiety. The Modern Language Journal, 70, 125-132.

Kronenberg, F. (2017). Conclusion-From language centers to language learning spaces. In F. Kronenberg (Ed.), From language lab to language center and beyond: The past, present, and future of language center design (pp. 161-165). Auburn, AL: International Association for Language Learning Technology.

Modern Language Association. (2011). Learning another language: Goals and challenges [Executive Council statement]. Retrieved from https://www.mla.org/AboutUs/Governance/Executive-Council/Executive-Council-Actions/2011/Learning-AnotherLanguage-Goals-and-Challenges

O’Maggio-Hadley, A. (2001). Teaching language in context. Boston, MA: Heinle \& Heinle.

SANS Inc. (2019). Why a language lab technology platform today? [Web Page]. Retrieved May 23, 2019, from https://www.sansinc.com/

Skehan, P. (1989). Individual differences in second-language learning. London, England: Arnold.

Young, D. J. (1991). Creating a low-anxiety classroom environment: What does language anxiety research suggest? Modern Language Journal, 75, 426-448. 